\title{
Editorial
}

\section{The secondary effects of a common market}

Helmut Becker, Deloitte Haskins \& Sells International, Düsseldorf

In discussions on Europe 1992 taxes are only talked about from the perspective of those measures which are scheduled by the EC Commission. Therefore the interest is focused on the harmonization of VAT and consumer taxes, the elimination of border controls and the increase of the exchange of information between the European tax authorities. All these measures are directly aimed at the realization of a common market. Their results could therefore be defined as the primary effects of a common market. These effects are limited because the harmonization of the income taxes, business taxes, and property taxes is under consideration but very far from any solution. Therefore for a long period of time taxwise we will have to live in a Mini-Europe. The harmonized common market will meet a variety of un-harmonized tax systems.

Nevertheless the business world inside and outside of the EG prepares itself for the realization of Europe 92. Therefore a lot of preparation work and changes are going on. Most of these will not be neutral as far as taxation is concerned. They will result in tax consequences which are not directly attributed to the creation of a common market. Therefore they could be defined as secondary effects of a common market. Such secondary effects are very important. Nevertheless the tax literature is not yet dealing with them; they live in a shadow area.

After the border barriers have disappeared and foreign VAT is no longer a problem the significance of the group-owned distribution companies might decrease. Independent national dealers might insist on direct deliveries by the foreign producers - of course at a lower price. Other dealers, not so important, might not achieve the same result. However, due to these split prices the tax authorities of the importing state do now have two prices for the same good available instead of only one in former times. Therefore the margin of the group-owned distribution company might come under discussion. This raises new problems in the area of transfer pricing. The transfer pricing problem will become even more critical if an independent dealer from another Member State who is not impeded by any border barriers begins to deliver to the importing country, too. Then the national tax authorities will have three or more different prices for the same product available.

Let me also refer to a further secondary effect of the common market in connection with direct deliveries from the producer in one EC country to an independent dealer in the other country. If such a relationship improves, this results in more or less frequent visits of representatives of the producer to the dealer, and these representatives might take new orders with them. As they are dependent agents authorized to conclude delivery contracts, this will result in a permanent establishment of the producer. In case such direct deliveries are performed in relation to different dealers in different countries, there might be a remarkable increase of permanent establishments. This secondary effect of the common market should be considered in time.

To end with a third example. Up to now the different Member States of the EC represented different national markets managed locally. A common market will very likely result in a centralized management. This could be connected with serious tax problems. The catchwords are profit realization due to a transfer of the management and where the place of management is located following the transfer. These are also secondary results of the common market which have to be considered. Furthermore the location of a centralized management has to be considered. In this issue an article describing and comparing the Coordination Centres in Belgium and Germany will deal with that subject. 